\title{
Evaluation of the Management of Hyperlipidemia and Hypertension in an Outpatient Cardiac Transplant Clinic
}

\author{
Jane J. Xu' ${ }^{1}$, Ilene Burton ${ }^{2}$, Wayne J. Tymchak ${ }^{3,4}$, Glen J. Pearson ${ }^{3,4}$ \\ ${ }^{1}$ Alberta Health Services, Pharmacy Services, Edmonton, Canada \\ ${ }^{2}$ Alberta Health Services, Transplant Services, Edmonton, Canada \\ ${ }^{3}$ University of Alberta, Division of Cardiology, Edmonton, Canada \\ ${ }^{4}$ Mazankowski Alberta Heart Institute, Edmonton, Canada \\ Email: Glen.Pearson@ualberta.ca
}

Received 11 December 2015; accepted 24 January 2016; published 27 January 2016

Copyright (C) 2016 by authors and Scientific Research Publishing Inc.

This work is licensed under the Creative Commons Attribution International License (CC BY). http://creativecommons.org/licenses/by/4.0/

(c) $\underset{\mathrm{EY}}{0}$ Open Access

\section{Abstract}

Background: Allograft coronary artery disease (ACAD) is a common cause of morbidity and mortality post-orthotopic heart transplantation (OHT). ACAD progression may be reduced by modifying cardiovascular risk factors, such as hyperlipidemia and hypertension. We sought to evaluate the management of hyperlipidemia and hypertension among OHT recipients followed in an outpatient cardiac transplant clinic. Objective: The primary objective was to assess the proportion of OHT patients achieving both the recommended LDL target of $<2.0 \mathrm{mmol} / \mathrm{L}$ and BP targets of $<140 / 90 \mathrm{mmHg}$ (or $<\mathbf{1 3 0 / 8 0} \mathbf{m m H g}$ for diabetics) in an outpatient cardiac transplant clinic. Methods: A cross-sectional retrospective analysis of the medical records of all adult OHT recipients actively followed in our outpatient cardiac transplant between January-March 2009. Results: Of the 193 patients included, both the low-density lipoprotein (LDL) cholesterol and blood pressure (BP) targets were achieved in $111(57.5 \%)$ patients. The LDL target alone was achieved by 140 (72.5\%) patients and the BP target alone by $153(79.3 \%)$ patients. Statins were prescribed in 183 $(94.8 \%)$ patients with a mean LDL of $1.81 \mathrm{mmol} / \mathrm{L}( \pm 0.55)$. Angiotensin converting enzyme-inhibitors [ACE-I] (or angiotensin receptor blockers [ARB]) were prescribed in 154 (79.8\%) patients, diltiazem in $101(52.3 \%)$ patients, and both in $85(44.0 \%)$ patients, with a mean BP of 124.2/77.8 mmHg ( $\pm 13.6 / 8.2)$. Adverse reactions related to statins, ACE-inhibitors or diltiazem were uncommon and rarely resulted in drug discontinuation. Conclusions: Guideline recommended that LDL and BP targets are achievable in a significant proportion of OHT recipients. The high utilization rates of statins for dyslipidemia and ACE-I (or ARB) and diltiazem for BP were consistent with guideline recommendations for the prevention of ACAD. Despite concerns regarding the potential for pharmacokinetic drug interactions in OHT patients, the reported rates of any drug intolerance to these medications were low in our population. 


\section{Keywords}

\section{Cardiac Transplant, Allograft Coronary Artery Disease, Graft Vaculopathy, Dyslipidemia, Hypertension}

\section{Introduction}

Heart transplantation is a life-saving medical intervention indicated for highly selected patients with end-stage heart disease; however, $<200$ heart transplants are performed annually across Canada [1]. Allograft coronary artery disease (ACAD), a rapidly progressive form of atherosclerosis in orthotopic heart transplantation (OHT) recipients, is a common cause of morbidity and mortality [2]. ACAD is characterized by intimal proliferation, luminal stenosis of epicardial branches, and occlusion of smaller arteries [3]. By 10 years post-transplant, $>50 \%$ of surviving recipients have angiographic ACAD [4]. Both immunologic risk factors and non-immunologic risk factors are reported to be implicated [3]. It has been reported that $93 \%$ of surviving recipients have hyper-lipidemia and 99\% have hypertension by 10 years post-OHT [4]. The only definitive treatment for ACAD is re-transplantation, but this not only poses risks for the patient but also causes ethical dilemmas for clinicians because of the scarcity of donor organs [3]. Because of the significant influence ACAD has on morbidity and mortality, it is important to focus on preventing this silent progressive disease, rather than treating its consequences.

Hyperlipidemia is the most consistently associated metabolic risk factor for the development of ACAD in the OHT recipient and can be caused by factors such as pre-transplant hyperlipidemia, immunosuppressant medications, obesity, and diabetes [2] [5] [6]. Low-density lipoprotein (LDL) is significantly associated with coronary intimal thickening and graft dysfunction [3] [7]. Prospective, randomized studies have demonstrated that statins reduce all-cause mortality at 1-year post-OHT [5] [8]. Kobashigawa concluded that the early use of pravastatin safely lowered cholesterol levels, decreased the incidence of major rejection, improved 1-year survival, and reduced the development of ACAD [9]. Follow-up studies have shown that these benefits were maintained for 10 years [10]. Similar findings are reported with use of simvastatin [11]-[13]. Other statins have shown benefit in smaller studies and appear to be safe and effective in aggressively lowering low-density lipoprotein (LDL) cholesterol in OHT recipients where other statins failed to reach therapeutic goals [14]-[16].

Based on this evidence, the Canadian Cardiovascular Society (CCS) consensus on cardiac transplantation recommends all patients receive a statin after cardiac transplantation regardless of their baseline LDL [2]. Since OHT recipients are at significant risk of ACAD, it is reasonable to adopt the LDL targets currently recommended for high risk CAD patients [6]. The current recommended goal for high-risk patients is LDL $<2.0 \mathrm{mmol} / \mathrm{L}$ [17].

Non-statin lipid-lowering agents are not commonly used in OHT recipients due to interactions with calcineurin inhibitors (CNIs) and statins, or adverse effects [5] [6] [18]. Patients who are intolerant of statins or who do not reach target lipid levels may require the addition of a second agent such as ezetimibe [19] [20]. However, lower initial doses and close monitoring are needed due to reports of supra-therapeutic response to ezetimibe when taken with cyclosporine [21].

The adverse drug reactions associated with statins that generate the greatest apprehension among patients are myotoxicity (myopathy and myositis) and increased liver enzymes. However, many of the statin trials have failed to demonstrate severe adverse effects or showed reversible creatine kinase (CK) elevations, suggesting that statins are safe [9] [11] [14]-[16]. Statin safety trials concluded that since the incidence of severe complications is low, statins are safe in this population if closely monitored [22] [23].

Hypertension in OHT patients can occur within days of transplantation as a consequence of immunosuppressive therapy and the denervation of cardiac volume receptors [24] [25]. The CNIs increase endothelin-1, decrease nitric oxide (NO), and activate the renin-angiotensinaldosterone system (RAAS), resulting in vasoconstriction and elevation in blood pressure (BP) [25]. Additionally, due to the denervation of cardiac volume receptors, volume expansion from salt loading fails to suppress the RAAS, therefore producing hypertension [26].

Angiotensin-converting enzyme-inhibitors (ACE-Is) can blunt the effects of the neurohormonal systems that fail to respond to volume expansion and can enhance the activation of $\mathrm{NO}$ [27]. Calcium channel blockers (CCBs), 
particularly diltiazem, inhibit the vasoconstriction associated with cyclosporine by blocking the calcium channels [25]. The benefits of ACE-Is and CCBs may extend beyond their antihypertensive effects [25] [27]-[30].

Canadian guidelines for cardiac transplantation recommend that if an antihypertensive is required, diltiazem or an ACE-I should be considered first-line due to the potential benefits in reducing ACAD [2]. For OHT patients who have concurrent diabetes, it is appropriate to target a BP goal of $<130 / 80 \mathrm{mmHg}$ adopted from the Canadian Hypertension Education Program (CHEP) guidelines. For OHT patients without diabetes, the recommended BP goal of $<140 / 90 \mathrm{mmHg}$ from CHEP is endorsed [31]. Commonly reported adverse effects of ACE-Is in the studies included hypotension and increased serum creatinine [24]. Diltiazem has been reported to cause sinus bradycardia [29] and peripheral edema [24]. Concomitant use of diltiazem and cyclosporine may result in increased cyclosporine levels secondary to CYP 450 interactions; however, this is an exploitable drug interaction [29].

A survey of 59 American heart transplant centers revealed that statin therapy was included in the post-OHT protocol in $85 \%$ of centers [32]. Despite proportion of patients on statins and the low rate of adverse drug reactions, only 58.5\% of adult cardiac transplant patients achieve an institutional LDL target of $<2.6 \mathrm{mmol} / \mathrm{L}$ [32]. Since ACAD is a significant contributor to morbidity and mortality, it is essential to reduce the progression by treating modifiable risk factors, such as hyperlipidemia and hypertension.

The purpose of this study was to evaluate the management of hyperlipidemia and hypertension among OHT recipients followed in the outpatient cardiac transplant clinic at the University of Alberta. Characterizing the proportion of patients achieving LDL and BP targets and the current patterns of use of lipid-lowering and antihypertensive agents will assist in improving the medical management of heart transplant recipients.

The primary objective was to assess the proportion of OHT patients achieving both the LDL target of $<2.0$ $\mathrm{mmol} / \mathrm{L}$ and BP targets of $<140 / 90 \mathrm{mmHg}$ or $<130 / 80 \mathrm{mmHg}$ for diabetics in an outpatient cardiac transplant clinic. Secondary objectives included the assessment of: 1) the proportion of patients achieving the LDL target of $<2.0 \mathrm{mmol} / \mathrm{L}$; 2) the proportion of patients currently achieving the BP targets of $<130 / 80 \mathrm{mmHg}$ for diabetics (patients taking anti-diabetic agents or with a fasting plasma glucose $>7 \mathrm{mmol} / \mathrm{L}$ ) or $<140 / 90 \mathrm{mmHg}$ for all others; and 3) the current usage patterns and intolerance to lipid-lowering and antihypertensive agents among OHT recipients.

\section{Methods}

\subsection{Design and Patient Population}

This study was a cross-sectional, retrospective analysis of all post-OHT patients being actively followed and collaboratively managed in the outpatient cardiac transplant clinic at the University of Alberta. Patients were included if they had undergone OHT and were $>18$ years old. Patients who received OHT at the University of Alberta Hospital but were actively being followed in another transplant clinic were excluded from the analysis.

\subsection{Data Collection}

A standardized case report form was used to extract information from the patients' clinic charts. Information was collected between January to March 2009 from the charts by a single investigator and included: 1) demographic data; 2) most recent fasting lipid profile; 3) BP readings taken during the last three clinic visits; 4) description of statins, ACE-Is, and diltiazem therapies; 5) documented intolerances or adverse effects associated with statins, ACE-Is, and diltiazem. Elevated ALT and AST was defined as $>3$ times the upper limit of normal (ULN), myalgia as muscle ache or weakness without CK elevation, myositis as CK elevation of $>3$ times but $<10$ times the ULN, and rhabdomyolysis as muscle symptoms with CK elevation of $>10$ times the ULN. Elevated creatinine was defined as $>30 \%$ increase from baseline and hyperkalemia was defined as $>5.0 \mathrm{mmol} / \mathrm{L}$.

\subsection{Sample Size and Data Analysis}

The sample size was based on the 209 post-OHT patients currently followed in the cardiac transplant clinic at the University of Alberta. Descriptive statistical analysis was performed using Microsoft Access and Excel. Documented intolerances associated with statins, ACE-Is, and diltiazem were described using the Naranjo algorithm [33]. The study was approved by the Health Research Ethics Board of the University of Alberta. 


\section{Results}

\subsection{Patient Characteristics}

Between 1985 and January 2009, 613 patients received heart transplants at the University of Alberta. Of those, 404 patients were excluded from the study (deceased, combined heart and lung transplants, orpediatric transplant). From 209 eligible patients, 16 patients were excluded due to being either lost to follow-up or being routinely followed by another clinic. A total of 193 patients were included (Figure 1). Demographic characteristics of included patients are summarized in Table 1 . The patient population consisted of $76.7 \%$ maleswith a mean age of $59.2 \pm 13.0$ years, who were a mean $8.2 \pm 4.8$ years post-OHT. ACAD was diagnosed by coronary angiography with or without myocardial scintigraphy in 43 (22.3\%) patients.

\subsection{Primary Objective}

A total of 111 (57.5\%) patients achieved both the LDL target of $<2.0 \mathrm{mmol} / \mathrm{L}$ and the BP target of $<140 / 90$ mmHg (or $<130 / 80 \mathrm{mmHg}$ for diabetics).

\subsection{Secondary Objectives}

Of the 193 patients, 140 (72.5\%) patients achieved the LDL target of $<2.0 \mathrm{mmol} / \mathrm{L}$. Patients who were prescribed a statin were more likely to reach this goal (Table 1 ). The mean LDL was $1.81 \pm 0.55 \mathrm{mmol} / \mathrm{L}$ for the entire cohort, $1.78 \pm 0.49 \mathrm{mmol} / \mathrm{L}$ for patients prescribed a statin and $2.43 \pm 1.09 \mathrm{mmol} / \mathrm{L}$ for those who were not (Table 1). For patients who did not achieve the LDL target, the mean LDL was $2.43 \pm 0.57 \mathrm{mmol} / \mathrm{L}$.

The BP target of either $<140 / 90 \mathrm{mmHg}$ or $<130 / 80 \mathrm{mmHg}$ was achieved by 153 (79.3\%) patients. The mean SBP of all patients was $124.2 \pm 13.6 \mathrm{mmHg}$, and the DBP was $77.8 \pm 8.2 \mathrm{mmHg}$ (Table 2). These numbers did not differ greatly for patients who were or were not prescribed an ACE-I (or ARB) or diltiazem. For patients who did not achieve the $<140 / 90 \mathrm{mmHg}$ or the $<130 / 80 \mathrm{mmHg}$ target, their mean BP was $144.4 \pm 11.3 \mathrm{mmHg}$ (SBP) and $87.9 \pm 11.4 \mathrm{mmHg}$ (DBP) and $136.5 \pm 11.9 \mathrm{mmHg}$ (SBP) and $81.4 \pm 5.2 \mathrm{mmHg}$ (DBP) respectively.

Statins were prescribed in $183(94.8 \%)$ patients with an atorvastatin-equivalent dose of $27.7 \pm 23.8 \mathrm{mg}$ once daily (Table 2). Atorvastatin (88.1\%) was the most commonly prescribed statin, followed by pravastatin (3.1\%) and simvastatin (2.6\%) (Table 2). The next two commonly used lipid-lowering agents were ezetimibe (12.4\%) and fish oil (2.1\%). Of 193 patients, 81.9\% were on one lipid-lowering agent and 14.0\% were on two lipidlowering agents.

For the use of antihypertensive agents, 88.1\% of patients were on either or both an ACE-I (or ARB) and diltiazem. ACE-Is (or ARBs) were prescribed in 154 (79.8\%) patients, diltiazem in 101 (52.3\%) patients, and both in 85 (44.0\%) patients. The rates of prescribing for additional classes of antihypertensive agents were low, except for thiazide diuretics (Figure 2). Of the 193 patients, 22.3\% were on one antihypertensive agent, 32.1\% were on two, $22.8 \%$ were on three, $10.9 \%$ were on four, and $2.1 \%$ were on five.

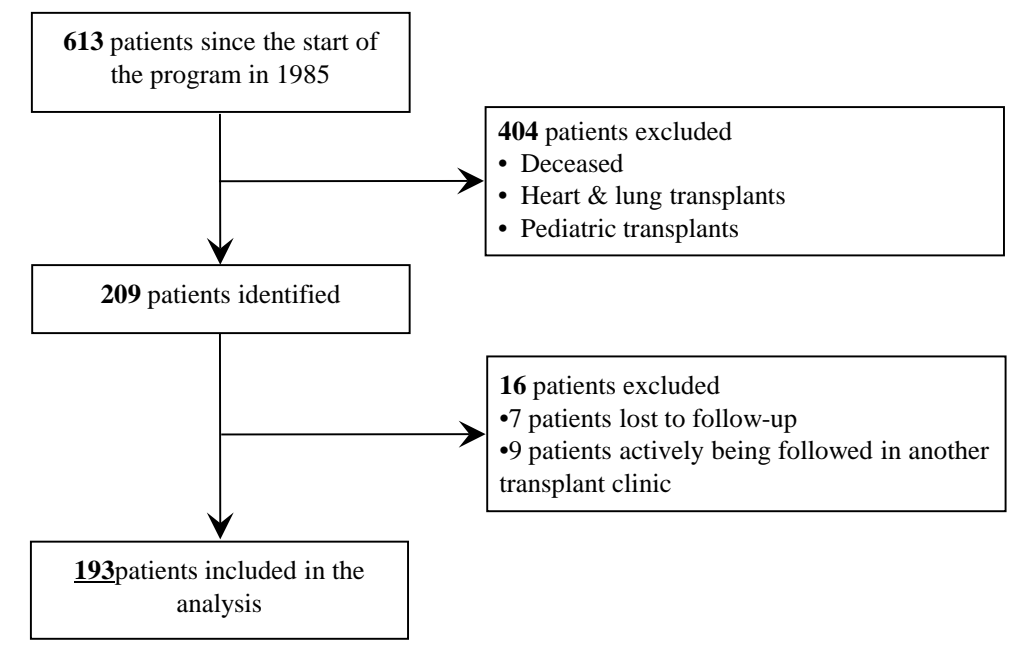

Figure 1. Flow diagram of patient selection. 
Table 1. Patient demographics.

\begin{tabular}{|c|c|c|c|c|c|}
\hline \multirow[b]{2}{*}{ Characteristic } & \multicolumn{5}{|c|}{ Patients } \\
\hline & All $(\mathrm{n}=193)$ & $\begin{array}{c}\text { Prescribed } \\
\text { statin }(n=183)\end{array}$ & $\begin{array}{l}\text { Not prescribed } \\
\text { statin }(\mathrm{n}=10)\end{array}$ & $\begin{array}{c}\text { Prescribed } \\
\text { ACEI/ARB or } \\
\text { CCB }(\mathrm{n}=170)\end{array}$ & $\begin{array}{l}\text { Not prescribed } \\
\text { ACEI/ARB or } \\
\text { CCB }(n=23)\end{array}$ \\
\hline \multicolumn{6}{|l|}{ Age (y) } \\
\hline Mean \pm SD & $59.2 \pm 13$ & $59.6 \pm 12.6$ & $52.7 \pm 11.4$ & $59.4 \pm 12.4$ & $57.8 \pm 16.9$ \\
\hline Range & $19.8-88.9$ & $19.8-88.9$ & $21.7-72.8$ & $22.4-88.9$ & $19.8-75.6$ \\
\hline Gender, male (\%) & $148(76.7)$ & $142(77.6)$ & $6(60)$ & 129 (75.9) & $19(82.6)$ \\
\hline \multicolumn{6}{|l|}{ Height (cm) } \\
\hline Mean \pm SD & $171.8 \pm 9.0$ & $171.8 \pm 9.0$ & $171.8 \pm 9.8$ & $172.0 \pm 8.9$ & $170.4 \pm 9.3$ \\
\hline Range & $147.5-193$ & $147.5-193$ & $157-186$ & $147.5-193$ & $152-183$ \\
\hline \multicolumn{6}{|l|}{ Weight (kg) } \\
\hline Mean \pm SD & $84.2 \pm 19$ & $84.0 \pm 18.5$ & $87.4 \pm 28$ & $84.9 \pm 19.4$ & $78.3 \pm 15.4$ \\
\hline Range & $31.4-151.6$ & $48.2-151.6$ & $31.4-131.8$ & $31.4-151.6$ & $48.8-113.2$ \\
\hline \multicolumn{6}{|c|}{ Time since transplant (y) } \\
\hline Mean \pm SD & $8.2 \pm 4.8$ & $8.2 \pm 4.9$ & $8.2 \pm 2.2$ & $8.2 \pm 4.7$ & $8.2 \pm 5.3$ \\
\hline Range & $0.1-22.6$ & $0.1-22.6$ & $4.7-12.1$ & $0.5-22.6$ & $0.1-19.5$ \\
\hline \multicolumn{6}{|c|}{ Indication for transplant, n (\%) } \\
\hline CAD & $92(50.3)$ & $87(47.5)$ & $5(50)$ & $81(47.6)$ & $11(47.8)$ \\
\hline $\mathrm{CM}$ & 75 (38.9) & $71(38.8)$ & $4(40)$ & $67(39.4)$ & $8(34.8)$ \\
\hline Dilated CM & $42(21.8)$ & 39 (21.3) & $3(30)$ & $38(22.4)$ & $4(17.4)$ \\
\hline Idiopathic CM & 23 (11.9) & $23(12.6)$ & 0 & $20(11.8)$ & $3(13)$ \\
\hline Hypertrophic CM & $5(2.6)$ & $5(2.7)$ & 0 & $4(2.4)$ & $1(4.3)$ \\
\hline ACAD-repeat OHT & $7(3.6)$ & $7(3.8)$ & 0 & $6(3.5)$ & $1(4.3)$ \\
\hline Others & $19(9.8)$ & $18(9.8)$ & $1(10)$ & $16(9.4)$ & $3(13)$ \\
\hline \multicolumn{6}{|c|}{ Immunosuppressive regimen, n (\%) } \\
\hline Cyclosporine & 119 (61.7) & $114(62.3)$ & $5(50)$ & 105 (61.8) & $14(60.9)$ \\
\hline Tacrolimus & $73(37.8)$ & $69(37.7)$ & $4(40)$ & $64(37.6)$ & $9(39.1)$ \\
\hline MMF & 135 (69.9) & $126(68.9)$ & $9(90)$ & $120(70.6)$ & $15(65.2)$ \\
\hline Azathioprine & $27(14)$ & $27(14.8)$ & 0 & $24(15.1)$ & $3(13.0)$ \\
\hline Corticosteroid & $40(20.7)$ & 36 (19.7) & $4(40)$ & 32 (18.8) & $8(34.8)$ \\
\hline Sirolimus & $21(10.9)$ & $19(9.8)$ & $2(20)$ & $18(10.6)$ & $3(13)$ \\
\hline Everolimus & $3(1.6)$ & $3(1.6)$ & 0 & $2(1.3)$ & $1(4.3)$ \\
\hline ACAD, n (\%) & $43(22.3)$ & 40 (21.9) & $3(30)$ & $36(21.2)$ & $7(30.4)$ \\
\hline \multicolumn{6}{|c|}{ Lipid $(m m o l / L) ;$ mean \pm SD } \\
\hline $\mathrm{TC}$ & $3.67 \pm 0.77$ & $3.63 \pm 0.69$ & $4.35 \pm 1.57$ & - & - \\
\hline TG & $1.61 \pm 1.04$ & $1.63 \pm 1.03$ & $1.48 \pm 1.27$ & - & _ \\
\hline HDL-C & $1.12 \pm 0.39$ & $1.11 \pm 0.37$ & $1.24 \pm 0.62$ & - & - \\
\hline LDL-C & $1.81 \pm 0.55$ & $1.78 \pm 0.49$ & $2.43 \pm 1.09$ & - & - \\
\hline TC:HDL-C & $3.53 \pm 1.05$ & $3.49 \pm 1.00$ & $4.05 \pm 1.75$ & - & - \\
\hline \multicolumn{6}{|l|}{ BP (mmHg) } \\
\hline $\mathrm{SBP}^{\mathrm{a}}$ & $124.2 \pm 13.6$ & - & - & $124.6 \pm 13.9$ & $121.7 \pm 11.1$ \\
\hline $\mathrm{DBP}^{\mathrm{a}}$ & $77.8 \pm 8.2$ & - & - & $77.8 \pm 8.1$ & $77.9 \pm 8.3$ \\
\hline
\end{tabular}

ACEI = angiotensin converting enzyme inhibitor, $\mathrm{ARB}=$ angiotensin receptor blocker, $\mathrm{CAD}=$ coronary artery disease, $\mathrm{ACAD}=$ allograft coronary artery disease, $\mathrm{CCB}$ = calcium channel blocker, $\mathrm{CM}=$ cardiomyopathy, $\mathrm{DBP}=$ diastolic blood pressure, HDL-C = high-density lipoprotein, $\mathrm{LDL}-\mathrm{C}=$ low-density lipoprotein, MMF = mycophenolate mofetil, $\mathrm{OHT}=$ orthotopic heart transplant, $\mathrm{SBP}=$ systolic blood pressure, $\mathrm{TC}=$ total cholesterol, $\mathrm{TG}=$ triglyceride. 
Table 2. Pattern of use of statins, ACE-inhibitors, and non-dihydropyridine calcium channel blockers.

\begin{tabular}{|c|c|c|c|c|}
\hline Medications & No. of patients, $n=193(\%)$ & Strength ${ }^{\mathrm{a}}$ (mg) & Route & Directions \\
\hline \multicolumn{5}{|l|}{ Statins } \\
\hline Atorvastatin & $170(88.1)$ & $28.9 \pm 24.0$ & $\mathrm{PO}$ & QD (x167) \& Q2D (x3) \\
\hline Pravastatin & $6(3.1)$ & $31.3 \pm 28.9$ & $\mathrm{PO}$ & QD \\
\hline Simvastatin & $5(2.6)$ & $26.0 \pm 13.4$ & $\mathrm{PO}$ & QD \\
\hline Rosuvastatin & $1(0.5)$ & 20 & $\mathrm{PO}$ & QD \\
\hline Lovastatin & $1(0.5)$ & 5 & $\mathrm{PO}$ & QD \\
\hline Fluvastatin & 0 & - & - & - \\
\hline None & $10(5.2)$ & - & - & - \\
\hline Atorvastatin-equivalent ${ }^{\mathbf{b}}$ & $183(94.8)$ & $27.7 \pm 23.8$ & $\mathrm{PO}$ & QD (x180) \& Q2D (x3) \\
\hline \multicolumn{5}{|l|}{ ACE-inhibitors } \\
\hline Quinapril & $102(52.8)$ & $29.5 \pm 15.3$ & $\mathrm{PO}$ & QD \\
\hline Ramipril & $16(8.3)$ & $7.1 \pm 3.6$ & $\mathrm{PO}$ & $\mathrm{QD}(\mathrm{x} 15)$ \& BID (x1) \\
\hline Lisinopril & $6(3.1)$ & $17.5 \pm 8.8$ & $\mathrm{PO}$ & QD \\
\hline Enalapril & $3(1.6)$ & $7.5 \pm 4.3$ & $\mathrm{PO}$ & QD (x2) \& BID (x1) \\
\hline \multicolumn{5}{|l|}{ Non-dihydropyridine CCB } \\
\hline Diltiazem & $101(52.3)$ & $218.3 \pm 93.9$ & $\mathrm{PO}$ & QD \\
\hline
\end{tabular}

$\mathrm{ACE}=$ angiotensin converting enzyme, $\mathrm{BID}=$ twice daily, $\mathrm{CCB}=$ calcium channel blocker, $\mathrm{PO}=$ per os (by mouth), $\mathrm{QD}=$ once daily, $\mathrm{Q} 2 \mathrm{D}=$ every two days. ${ }^{\mathrm{a}}$ Mean $\pm \mathrm{SD}$. ${ }^{\mathrm{b}}$ Atorvastatin $10 \mathrm{mg}=$ rosuvastatin $5 \mathrm{mg}=\operatorname{simvastatin} 20 \mathrm{mg}=$ pravastatin $40 \mathrm{mg}=$ lovastatin $40 \mathrm{mg}=$ fluvastatin $80 \mathrm{mg}$.

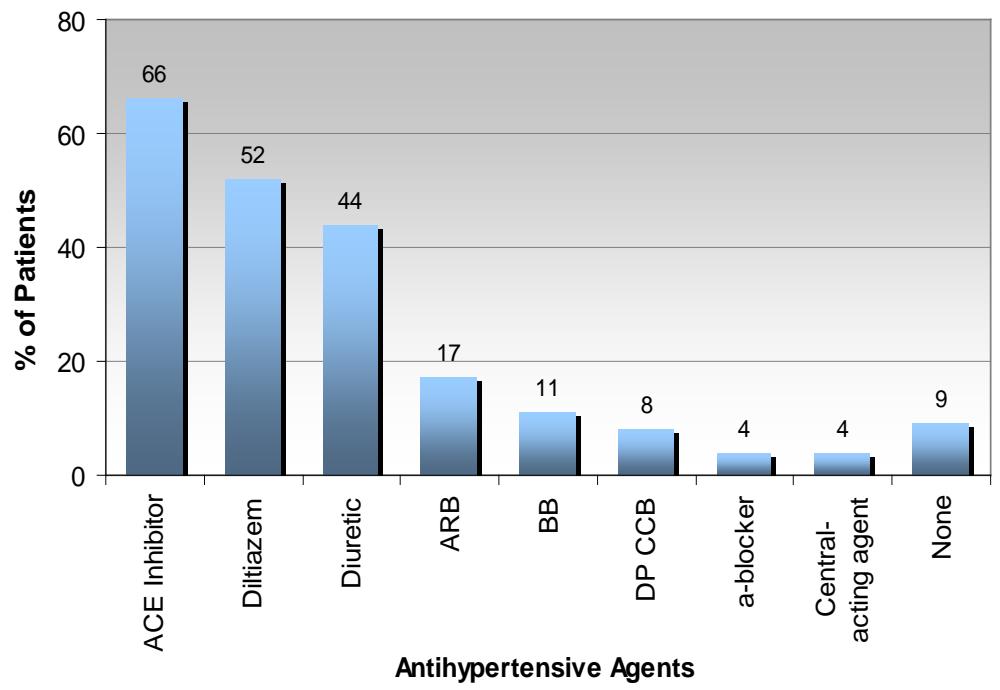

Figure 2. Proportion of patients taking antihypertensive agents by class.

Among the 183 patients prescribed a statin, a total of 27 (14.8\%) patients had some statin-related intolerance, of which 20 (10.9\%) had slightly elevated CK $(<3$ times the ULN) and 11 (6.0\%) reported myalgia (Table 3). Of the 127 patients who were prescribed an ACE-I, 37 (29.1\%) patients had ACE-I-related intolerance, of which 27 (21.3\%) had minor elevations in serum creatinine and 7 (5.5\%) had hyperkalemia. Of the 101 patients who were prescribed diltiazem, 11 (10.9\%) patients had diltiazem-related intolerances, of which 8 (7.9\%) had lower leg edema. Using the Naranjo algorithm, it was determined that none of the intolerances were classified as "definite” adverse drug reactions; rather, most were determined to be either “probable” or “possible” reactions.

\section{Discussion}

In our cardiac transplant clinic, 58\% of OHT patients achieved both an LDL target of $<2.0 \mathrm{mmol} / \mathrm{L}$ and a BP 
Table 3. Reported drug-related intolerances.

\begin{tabular}{cc}
\hline Patient reported intolerances on therapy & $\mathbf{N}(\mathbf{\%})$ \\
\hline Statins (n = 183) & $\mathbf{2 7}(\mathbf{1 4 . 8 )}$ \\
Elevated CK* & $20(10.9)$ \\
Myalgia & $11(6.0)$ \\
Elevated ALT & $2(1.1)$ \\
Hip pain & $1(0.5)$ \\
ACE-inhibitors (n = 127) & $\mathbf{3 7 ( 2 9 . 1 )}$ \\
Elevated serum creatinine** & $27(21.3)$ \\
Hyperkalemia & $7(5.5)$ \\
Dry cough & $3(2.4)$ \\
Dizziness or lightheadedness & $2(1.6)$ \\
Diltiazem (n = 101) & $\mathbf{1 1}(\mathbf{1 0 . 9 )}$ \\
Lower leg edema & $8(7.9)$ \\
Dizziness & $1(1.0)$ \\
Bradycardia & $1(1.0)$ \\
Stool incontinence & $1(1.0)$
\end{tabular}

*All elevated CK levels were between 250 - $750 \mathrm{U} / \mathrm{L}$. ${ }^{* *}$ Defined as $>30 \%$ increase from baseline serum creatinine.

target of $<140 / 90 \mathrm{mmHg}$ (or $<130 / 80 \mathrm{mmHg}$ for patients with diabetes). When separately assessing the proportion of patients achieving the LDL target, $73 \%$ of patients achieved the target. This proportion is much higher than that reported for non-cardiac transplantation patients with cardiovascular disease in general practices (30.5 $51.2 \%$ ) [34] [35]. If the higher LDL target of $<2.5 \mathrm{mmol} / \mathrm{L}$ was used, as previously recommended in the 2003 CCS guidelines, the proportion of patients who achieved this target increases to $93.8 \%$. Remarkably, the proportion of patients achieving this higher target LDL $(<2.5 \mathrm{mmol} / \mathrm{L})$ has been very consistent (93.3\%) since we first evaluated this in our patients $>5$ years ago [36]. This proportion of patients successfully treated to target is $35 \%$ higher than previously been reported, when the target LDL is comparable [32]. Even for patients who did not achieve the aggressive LDL target of $<2.0 \mathrm{mmol} / \mathrm{L}$, their mean LDL was only slightly (mean of $0.43 \mathrm{mmol} / \mathrm{L}$ ) above target. Similarly, the proportion of patients achieving the blood pressure goal (79\%) is higher than that reported for the general population (57\% - 58\%) [35] [37]. For those who did not achieve the goal, their BP readings were only 1 - $6 \mathrm{mmHg}$ above their target.

The successful attainment of these treatment goals may be due to the close patient monitoring and the collaborative interdisciplinary team approach operational in our outpatient cardiac transplant clinic. Consistent with the recommendations regarding dyslipidemia management, the majority of our patients were prescribed a statin (95\%). While published data supports the efficacy of pravastatin and simvastatin [9]-[13], our results expand the evidence with atorvastatin, as it was the most commonly prescribed agent in the class. In combination with or in place of statins, ezetimibe was the most common agent. Since $82 \%$ of our patients were on a regimen with only one lipid-lowering agent, our results suggest that most patients can achieve the LDL target with monotherapy. Also, consistent with the CCS recommendation regarding hypertension management, $88 \%$ of our patients were managed with either one or both an ACE-I (or ARB) and diltiazem. Two or more antihypertensive agents were used in $78 \%$ of patients, demonstrating that multiple antihypertensive agents are often required for the management of hypertension in OHT recipients.

Previous studies have reported up to $20 \%$ of OHT recipients may suffer adverse effects of initial statin therapy; however, problems resolve with close monitoring and severe adverse events are rare [9] [11] [14]-[16] [22] [23]. Our data is consistent with these findings and demonstrates a similar low incidence of medication intolerance. Although 15\% of patients had statin-related intolerances including minor CK or ALT elevations and myalgias, none were classified as definite, rather as possible or probable reactions. Furthermore, there were no documented cases of either myositis or rhabdomyolysis among patients on statin therapy. Only 7 patients had documented intolerances or contraindications that were severe enough to warrant discontinuation of statin therapy. Elevated serum creatinine was a common intolerance of ACE-Is; however, all of these were determined to be 
either possible or doubtful reactions. This can be explained by the fact that, independent of ACE-Is, renal insufficiency is often a co-morbidity among cardiac transplantation recipients caused by concurrent long-term therapy with CNIs. Similarly, immunosuppressant agents also promote fluid retention, and in combination with diltiazem, can lead to a worsening of lower extremity edema. Although the incidences of the intolerances may seem more common than the general population, they are not attributable to single agents. This reinforces the need for close follow-up monitoring in this patient population.

This study was a cross-sectional retrospective analysis; therefore, it has several limitations. Firstly, cholesterol and serum creatinine levels were collected from the most recent clinic follow-up laboratory results; therefore, trends or fluctuations were not captured or evaluated. Secondly, the BP readings were taken from clinic readings, and discrepancies may exist from home readings if patients had white coat syndrome. In attempt to control for this possible discrepancy, three BP readings from the last 3 clinic visits were used to calculate the average BP for each patient. Thirdly, we made no attempt to evaluate or ensure compliance to medications directly. However, compliance is routinely assessed at each follow-up clinic visit, and any evidence of non-adherence is documented. Fourthly, the appropriateness of a patient not being prescribed drug therapy was not evaluated. The avoidance of lipid-lowering or antihypertensive therapy may have been appropriate if there was an absolute contraindication. And finally, since this was a cross-sectional evaluation of the management of hyperlipidemia and hypertension, we cannot draw conclusions regarding how successful treatments to guideline targets have impacted clinical outcomes such as ACAD. Nevertheless, the rate of ACAD diagnosed in our study population (22.3\%) appears to be significantly lower than reported in the literature (53\% by 10-year), which may be the result of our high degree of success in modifying these risk factors.

\section{Conclusion}

It is possible to successfully achieve the guideline recommended LDL-cholesterol target of $<2 \mathrm{mmol} / \mathrm{L}$ and the recommended BP target of $<140 / 90 \mathrm{mmHg}$ (or $<130 / 80 \mathrm{mmHg}$ for diabetic patients) in a significant proportion of OHT recipients. The high utilization rates of statins for dyslipidemia and ACE-Is (or ARBs) and diltiazem for hypertension were consistent with the CCS consensus recommendations for the prevention of ACAD. Despite concerns regarding the potential for pharmacokinetic drug interactions due to complex poly-pharmacy in OHT patients, the reported rates of any drug intolerance to the medications were low in our population.

\section{References}

[1] (2012) E-Statistics Report on Organ Transplants, Waiting Lists and Donor Statistics, 2012 Summary Statistics. Ottawa (ON): Canadian Institute for Health Information. http://www.cihi.ca/CIHI-ext-portal/pdf/internet/REPORT_STATS2012_PDF_EN

[2] Ross, H., Hendry, P., Dipchand, A., Giannetti, N., Hirsch, G., Isaac, D., et al. (2003) Canadian Cardiovascular Society Consensus Conference on Cardiac Transplantation. Canadian Journal of Cardiology, 19, 620-654.

[3] Valantine, H. (2004) Cardiac Allograft Vasculopathy after Heart Transplantation: Risk Factors and Management. Journal of Heart and Lung Transplantation, 23, S187-S193. http://dx.doi.org/10.1016/j.healun.2004.03.009

[4] Taylor, D.O., Edwards, L.B., Aurora, P., Christie, J.D., Dobbels, F., Kirk, R., et al. (2008) Registry of the International Society for Heart and Lung Transplantation: Twenty-Fifth Official Adult Heart Transplant Report-2008. Journal of Heart and Lung Transplantation, 27, 943-956. http://dx.doi.org/10.1016/j.healun.2008.06.017

[5] Wenke, K. (2004) Management of Hyperlipidaemia Associated with Heart Transplantation. Drugs, 64, 1053-1068. http://dx.doi.org/10.2165/00003495-200464100-00003

[6] Bilchick, K.C., Henrikson, C.A., Skojec, D., Kasper, E.K. and Blumenthal, R.S. (2004) Treatment of Hyperlipidemia in Cardiac Transplant Recipients. American Heart Journal, 148, 200-210. http://dx.doi.org/10.1016/j.ahj.2004.03.050

[7] Kobashigawa, J.A., Starling, R.C., Mehra, M.R., Kormos, R.L., Bhat, G., Barr, M.L., et al. (2006) Multicenter Retrospective Analysis of Cardiovascular Risk Factors Affecting Long-Term Outcome of de Novo Cardiac Transplant Recipients. Journal of Heart and Lung Transplantation, 25, 1063-1069. http://dx.doi.org/10.1016/j.healun.2006.05.001

[8] Mehra, M.R. and Raval, N.Y. (2004) Metaanalysis of Statins and Survival in de Novo Cardiac Transplantation. Transplantation Proceedings, 36, 1539-1541. http://dx.doi.org/10.1016/j.transproceed.2004.05.036

[9] Kobashigawa, J.A., Katznelson, S., Laks, H., Johnson, J.A., Yeatman, L., Wang, X.M., et al. (1995) Effect of Pravastatin on Outcomes after Cardiac Transplantation. New England Journal of Medicine, 333, 621-627. http://dx.doi.org/10.1056/NEJM199509073331003 
[10] Kobashigawa, J.A., Moriguchi, J.D., Laks, H., Wener, L., Hage, A., Hamilton, M.A., et al. (2005) Ten-Year FollowUp of a Randomized Trial of Pravastatin in Heart Transplant Patients. Journal of Heart and Lung Transplantation, 24, 1736-1740. http://dx.doi.org/10.1016/j.healun.2005.02.009

[11] Wenke, K., Meiser, B., Thiery, J., Nagel, D., von Scheidt, W., Steinbeck, G., et al. (1997) Simvastatin Reduces Graft Vessel Disease and Mortality after Heart Transplantation: A Four-Year Randomized Trial. Circulation, 96, 1398-1402. http://dx.doi.org/10.1161/01.CIR.96.5.1398

[12] Wenke, K., Meiser, B., Thiery, J., Nagel, D., von Scheidt, W., Krobot, K., et al. (2003) Simvastatin Initiated Early after Heart Transplantation: 8-Year Prospective Experience. Circulation, 107, 93-97. http://dx.doi.org/10.1161/01.CIR.0000043241.32523.EE

[13] Wenke, K., Meiser, B., Thiery, J. and Reichart, B. (2005) Impact of Simvastatin Therapy after Heart Transplantation an 11-Year Prospective Evaluation. Herz, 30, 431-432. http://dx.doi.org/10.1007/s00059-005-2685-6

[14] Patel, D.N., Pagani, F.D., Koelling, T.M., Dyke, D.B., Baliga, R.R., Cody, R.J., et al. (2002) Safety and Efficacy of Atorvastatin in Heart Transplant Recipients. The Journal of Heart and Lung Transplantation, 21, 204-210. http://dx.doi.org/10.1016/S1053-2498(01)00369-2

[15] Samman, A., Imai, C., Straatman, L., Frolich, J., Humphries, K. and Ignaszewski, A. (2005) Safety and Efficacy of Rosuvastatin Therapy for the Prevention of Hyperlipidemia in Adult Cardiac Transplant Recipients. The Journal of Heart and Lung Transplantation, 24, 1008-1013. http://dx.doi.org/10.1016/j.healun.2004.07.016

[16] O’Rourke, B., Barbir, M., Mitchell, A.G., Yacoub, M.H. and Banner, N.R. (2004) Efficacy and Safety of Fluvastatin Therapy for Hypercholesterolemia after Heart Transplantation: Results of a Randomised Double Blind Placebo Controlled Study. International Journal of Cardiology, 94, 235-240. http://dx.doi.org/10.1016/j.ijcard.2003.04.009

[17] Genest, J., McPherson, R., Frohlich, J., Anderson, T., Campbell, N., Carpentier, A., et al. (2009) Canadian Cardiovascular Society/Canadian Guidelines for the Diagnosis and Treatment of Dyslipidemia and Prevention of Cardiovascular Disease in the Adult-2009 Recommendations. Canadian Journal of Cardiology, 25, 567-579. http://dx.doi.org/10.1016/S0828-282X(09)70715-9

[18] Page II, R.L., Miller, G.G. and Lindenfeld, J. (2005) Drug Therapy in the Heart Transplant Recipient: Part IV: Drug-Drug Interactions. Circulation, 111, 230-239. http://dx.doi.org/10.1161/01.CIR.0000151805.86933.35

[19] Patel, A.R., Ambrose, M.S., Duffy, G.A., Cote, H. and DeNofrio, D. (2007) Treatment of Hypercholesterolemia with Ezetimibe in Cardiac Transplant Recipients. The Journal of Heart and Lung Transplantation, 26, 281-284. http://dx.doi.org/10.1016/j.healun.2007.01.008

[20] Shaw, S.M., Chaggar, P., Ritchie, J., Shah, M.K., Baynes, A.C., O’Neill, N., et al. (2009) The Efficacy and Tolerability of Ezetimibe in Cardiac Transplant Recipients Taking Cyclosporin. Transplantation, 87, 771-775. http://dx.doi.org/10.1097/TP.0b013e318198d7d0

[21] Koshman, S.L., Lalonde, L.D., Burton, I., Tymchak, W.J. and Pearson, G.J. (2005) Supratherapeutic Response to Ezetimibe Administered with Cyclosporine. Annals of Pharmacotherapy, 39, 1561-1565. http://dx.doi.org/10.1345/aph.1G015

[22] Marzoa-Rivas, R., Crespo-Leiro, M.G., Paniagua-Marin, M.J., Llinares-Garcia, D., Muniz-Garcia, J., Aldama-Lopez, G., et al. (2005) Safety of Statins When Response Is Carefully Monitored: A Study of 336 Heart Recipients. Transplantation Proceedings, 37, 4071-4073. http://dx.doi.org/10.1016/j.transproceed.2005.09.163

[23] Grigioni, F., Carigi, S., Potena, L., Fabbri, F., Russo, A., Musuraca, A.C., et al. (2006) Long-Term Safety and Effectiveness of Statins for Heart Transplant Recipients in Routine Clinical Practice. Transplantation Proceedings, 38, 1507-1510. http://dx.doi.org/10.1016/j.transproceed.2006.02.071

[24] Brozena, S.C., Johnson, M.R., Ventura, H., Hobbs, R., Miller, L., Olivari, M.T., et al. (1996) Effectiveness and Safety of Diltiazem or Lisinopril in Treatment of Hypertension after Heart Transplantation. Results of a Prospective Randomized Multicenter Trail. Journal of the American College of Cardiology, 27, 1707-1712. http://dx.doi.org/10.1016/0735-1097(96)00057-5

[25] Rockx, M.A. and Haddad, H. (2007) Use of Calcium Channel Blockers and Angiotensin-Converting Enzyme Inhibitors after Cardiac Transplantation. Current Opinion in Cardiology, 22, 128-132. http://dx.doi.org/10.1097/hco.0b013e3280210681

[26] Eisen, H.J. (2003) Hypertension in Heart Transplant Recipients: More than Just Cyclosporine. Journal of the American College of Cardiology, 41, 433-434. http://dx.doi.org/10.1016/S0735-1097(02)02821-8

[27] Erinc, K., Yamani, M.H., Starling, R.C., Crowe, T., Hobbs, R., Bott-Silverman, C., et al. (2005) The Effect of Combined Angiotensin-Converting Enzyme Inhibition and Calcium Antagonism on Allograft Coronary Vasculopathy Validated by Intravascular Ultrasound. The Journal of Heart and Lung Transplantation, 24, 1033-1038. http://dx.doi.org/10.1016/j.healun.2004.06.005

[28] Mehra, M.R., Ventura, H.O., Smart, F.W., Collins, T.J., Ramee, S.R. and Stapleton, D.D. (1995) An Intravascular Ul- 
trasound Study of the Influence of Angiotensin-Converting Enzyme Inhibitors and Calcium Entry Blockers on the Development of Cardiac Allograft Vasculopathy. American Journal of Cardiology, 75, 853-854. http://dx.doi.org/10.1016/S0002-9149(99)80432-9

[29] Schroeder, J.S., Gao, S.Z., Alderman, E.L., Hunt, S.A., Johnstone, I., Boothroyd, D.B., et al. (1993) A Preliminary Study of Diltiazem in the Prevention of Coronary Artery Disease in Heart-Transplant Recipients. The New England Journal of Medicine, 328, 164-170. http://dx.doi.org/10.1056/NEJM199301213280303

[30] Leenen, F.H., Coletta, E. and Davies, R.A. (2007) Prevention of Renal Dysfunction and Hypertension by Amlodipine after Heart Transplant. American Journal of Cardiology, 100, 531-535. http://dx.doi.org/10.1016/j.amjcard.2007.03.058

[31] Khan, N.A., Hemmelgarn, B., Herman, R.J., Rabkin, S.W., McAlister, F.A., Bell, C.M., et al. (2008) The 2008 Canadian Hypertension Education Program Recommendations for the Management of Hypertension: Part 2-Therapy. Canadian Journal of Cardiology, 24, 465-475. http://dx.doi.org/10.1016/S0828-282X(08)70620-2

[32] de Denus, S., Al-Jazairi, A., Loh, E., Jessup, M., Stanek, E.J. and Spinler, S.A. (2004) Dyslipidemias and HMG-CoA Reductase Inhibitor Prescription in Heart Transplant Recipients. Annals of Pharmacotherapy, 38, 1136-1141. http://dx.doi.org/10.1345/aph.1D535

[33] Naranjo, C.A., Busto, U., Sellers, E.M., Sandor, P., Ruiz, I., Roberts, E.A., et al. (1981) A Method for Estimating the Probability of Adverse Drug Reactions. Clinical Pharmacology \& Therapeutics, 30, 239-245. http://dx.doi.org/10.1038/clpt.1981.154

[34] Yan, A.T., Yan, R.T., Tan, M., Hackam, D.G., Leblanc, K.L., Kertland, H., et al. (2006) Contemporary Management of Dyslipidemia in High-Risk Patients: Targets Still Not Met. American Journal of Medicine, 119, 676-683. http://dx.doi.org/10.1016/j.amjmed.2005.11.015

[35] Saposnik, G., Goodman, S.G., Leiter, L.A., Yan, R.T., Fitchett, D.H., Bayer, N.H., et al. (2009) Applying the Evidence: Do Patients with Stroke, Coronary Artery Disease, or both Achieve Similar Treatment Goals? Stroke, 40, 1417-1424. http://dx.doi.org/10.1161/STROKEAHA.108.533018

[36] Pearson, G.J., Stewart, G.G., Burton, I., Chorney, S.G., Tymchak, W.J., Lalonde, L.D. and Burton, J.R. (2004) Successful Treatment to Guideline Recommended LDL Cholesterol Targets in Heart Transplant Recipients. Canadian Journal of Cardiology, 21, 241C.

[37] Farahani, P. and Levine, M. (2009) Goal Attainment for Multiple Cardiovascular Risk Factors in Community-Based Clinical Practice (a Canadian Experience). Journal of Evaluation in Clinical Practice, 15, 212-216. http://dx.doi.org/10.1111/j.1365-2753.2008.01002.x 